\title{
PEMODELAN ENTERPRISE ARCHITECTURE MENGGUNAKAN TOGAF PADA UNIVERSITAS X PALEMBANG
}

\author{
Lathifah $^{1)}$, Suaidah'), Muhammad Bambang F ${ }^{3)}$, M.Khairul Anam4), Fadli Suandi') \\ ${ }^{1,2}$ Fakultas Teknik dan Ilmu Komputer, Universitas Teknokrat Indonesia \\ ${ }^{3}$ Informatika, Universitas Mulawarman \\ ${ }^{4}$ Teknik Informatika, STMIK Amik Riau \\ ${ }^{5}$ Teknik Informatika, Politeknik Negeri Batam \\ 1,2 Jl. ZA.Pagar Alam No.9-11, Bandar Lampung \\ ${ }^{3}$ Jl. Barong Tongkok Kampus Gn.Kelua, Samarinda \\ ${ }^{4}$ Jl.Purwodadi Indah, km 10 Panam, Pekanbaru \\ ${ }^{5} \mathrm{Jl}$. Ahmad yani Batam Kota, Kepulauan Riau
}

Email: ${ }^{1}$ Lathifah@teknokrat.ac.id, , ${ }^{2}$ Suaidah@teknokrat.ac.id, ${ }^{3}$ bambang@.fkti.unmul.ac.id, khairulanam@sar.ac.id, ${ }^{5}$ fadli.suandi@polibatam.ac.id

\begin{abstract}
Today's education world sees importance of enterprise architecture in supporting operation of systems in accordance with business strategies. University $X$ is aligning business processes with information technology to be centralized, university $X$ currently has information system that is still accommodated in each faculty so it takes a long time and a lot of human resources to be gathered into one. With this information system alignment, it will facilitate all performance systematically in accordance with business processes in real time. Business processes at X Palembang University include business organization, data, applications, and technology used. The problem is that the current information systems running at X University are still difficult to integrate with one another. Therefore, a model will be made to integrate all information systems running at X Palembang University. TOGAF is used to determine the course of business processes, data, applications, and technology used for alignment of information systems and applications built. The results obtained are the modeling of enterprise architecture from business architecture, data architecture, application architecture, and technology architecture to support the running of information systems smoothly. The conclusion that can be drawn from the research is the design of enterprise architecture in the academic system, data architecture and technology obtained in this study which are integrated and connected. The business model strategy that is made must be able to have a complete and stable scope for a long time.
\end{abstract}

Keyword: Enterprise Architecture, Information System, TOGAF, University

\begin{abstract}
Abstrak
Dunia pendidikan saat ini memandang penting enterprise architecture dalam mendukung berjalannya system sesuai dengan strategi bisnis. Universitas X melakukan menyelaraskan proses bisnis dengan teknologi informasi menjadi terpusat, universitas $\mathrm{x}$ saat ini memiliki sistem informasi yang masih tertampung pada masing-masing fakultas sehingga membutuhkan waktu yang lama serta sumber daya manusia yang banyak untuk dikumpulkan menjadikan satu. Dengan adanya keselarasan sistem informasi tersebut akan mempermudah semua kinerja secara sistematis sesuai dengan proses bisnis secara real time. Proses bisnis pada Universitas x Palembang meliputi organisasi bisnis, data, aplikasi, dan teknologi yang digunakan. Permasalahannya yaitu sistem informasi yang berjalan pada Universitas $\mathrm{x}$ saat ini masih sulit terintegrasi satu sama lain. Maka dari itu akan dibuat sebuah model untuk mengintegrasikan seluruh sistem informasi yang berjalan di Universitas X Palembang. TOGAF digunakan untuk menentukan jalannya proses bisnis, data, aplikasi, dan teknologi yang digunakan untuk keselarasan sistem informasi beserta aplikasi yang dibangun. Hasil yang didapat yaitu adanya pemodelan enterprise architecture dari architecture bisnis, architecture data, architecture aplikasi, dan architecture teknologi untuk mendukung jalannya sistem informasi secara lancar. Kesimpulan yang dapat ditarik dari penelitian yaitu perancangan arsitekture enterprise di sistem akademik, arsitektur data dan teknologi yang didapat dalam penelitian ini yang saling terintergrasi dan terhubung. Strategi model bisnis yang dibuat harus dapat memiliki ruang lingkup yang lengkap dan stabil untuk waktu yang panjang.
\end{abstract}


Kata Kunci: Enterprise Architecture, Sistem Informasi, TOGAF, Universitas

\section{Pendahuluan}

Teknologi pada suatu organisasi, perusahaan, dan pemerintahan era sekarang sangat memiliki peran yang begitu besar. Universitas x Palembang memandang pentingnya enterprise architecture yang bergerak dibidang pendidikan. Hal ini dikarenakan untuk menyelaraskan proses bisnis dengan teknologi informasi menjadi terpusat, universitas $\mathrm{x}$ saat ini memiliki sistem informasi yang masih tertampung pada masing-masing fakultas sehingga membutuhkan waktu yang lama serta sumber daya manusia yang banyak untuk dikumpulkan menjadikan satu. Dengan adanya keselarasan sistem informasi tersebut akan mempermudah semua kinerja secara sistematis sesuai dengan proses bisnis secara real time. Proses bisnis pada Universitas x Palembang meliputi organisasi bisnis, data, aplikasi, dan teknologi yang digunakan. Permasalahannya yaitu sistem informasi yang berjalan pada Universitas x saat ini masih sulit terintegrasi satu sama lain. Maka dari itu akan dibuat sebuah model untuk mengintegrasikan seluruh sistem informasi yang berjalan di Universitas x Palembang.

Cara untuk menyelaraskannya yaitu dibutuhkan enterprise architecture untuk dijadikan gambaran serta acuan, dalam membuat sebuah model. Terutama saat proses pemodelan akan cenderung menjadi besar dan kompleks serta harus menentukan elemen mana yang harus dimodelkan, TOGAF digunakan untuk menentukan proses bisnis, data, aplikasi, dan teknologi yang digunakan untuk keselarasan sistem informasi dengan proses bisnis beserta aplikasi yang dibangun jangka panjang secara terstruktur agar sistem informasi di Universitas x Palembang bisa terpusat menjadi satu. Enterprise merupakan sekumpulan organisasi yang memiliki beberapa tujuan atau prinsip umum dan suatu garisan dasar [1]. Enterprise architecture merupakan suatu proses bisnis yang terkait dengan artefak, artefak meliputi lapisan architecture, komponen perangkat lunak, integrasi, proses-proses bisnis, strategi bisnis, dan infrastruktur [1]. Universitas membutuhkan enterprise architecture karena untuk memiliki infrastruktur teknologi informasi yang bagus pada universitas memerlukan investasi yang besar, pemanfaatan teknologi informasi sekarang relative kurang efisien dan efektif sehingga yang terjadi saat ini pengelolaan teknologi informasi masih belum selaras dengan strategi dan belum bisa digunakan dalam waktu yang panjang [2].

Penerapan aplikasi pada universitas mempengaruhi beberapa factor yaitu sumber daya, waktu, biaya, manfaat, serta factor sukses dalam implementasi [3]. Penerapan enterprise architecture di universitas $\mathrm{x}$ Palembang memiliki banyak tantangan dalam proses integrasi, maka dari itu diperlukan perancangan enterprise architecture yang baik agar terjadi keselarasan proses bisnis dan teknologi informasi pada universitas x Palembang. Apabila integrasi dilakukan dengan baik maka hasilnya baik pula, jika terjadi integrasi yang tidak baik maka dapat menyebabkan kegagalan pada proses secara keseluruhan [4].Pengujiann menggunakan TOGAF, TOGAF merupakan rancangan model architecture yang sesuai dengan visi dan misi Universitas $\mathrm{x}$ serta dapat diterapkan pada Universitas lain yang mempunyai kesamaan dalam proses bisnis[5]. Dalam pengembangan TOGAF meliputi empat jenis terkait architecture yang umum diterima sebagai himpunan bagian dari enterprise architecture yaitu architecture business, architecture application, architecture data, dan architecture technology [6] [7].

Framework TOGAF digunakan untuk menghasilkan blue print pada sistem yang dimana proses bisnis saling terintegrasi, serta mempercepat pendistribusian atau penyebaran informasi sehingga lebih efektif dan efesien [8]. Penerapan enterprise architecture pada perguruan tinggi memiliki banyak manfaat dari proses bisnis yang berjalan, integrasi data yang tehubung, aplikasi yang dipakai, dan teknologi yang digunakan mendukung jalanya universtas [9]. Model enterprise architecture dibuat untuk meningkatkan sistem informasi berdasarkan prioritas kebutuhan organisasi agar proses implementasi terukur secara sistematis agar mencapai tujuan strategi orgnisasi universitas [10].

sebuah rancangan infrastruktur teknologi informasi yang berifat adaftip dengan konsep yang di adopsi berupa teknologi virtualisasi server, serta pemanfaatan proses bisnis mampu berjalan efisien, efektif serta sesuai yang diinginkan manajemen [11] [16].

\section{Metode}

Tahapan-tahapan penelitian yang dilakukan oleh peneliti dari awal hingga akhir pada Gambar 1.

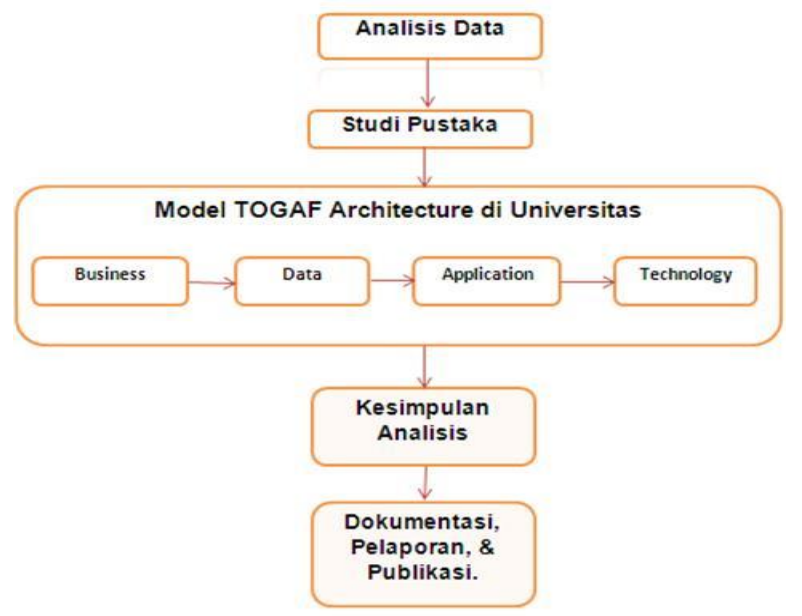

Gambar 1. Diagram Tahapan penelitian 


\subsection{Analisis Data}

Peneliti melakukan survei ke Universitas X Palembang untuk mengetahui data yang terkait dalam proses bisnis, aplikasi, dan teknologi yang digunakan. Metode pengumpulan data yang penelitian ini dilakukan dengan cara teknik observasi dan wawancara. Data yang didapat dijadikan acuan dalam membuat pemodelan enterprise architecture pada Universitas X Palembang.

\subsection{Studi Pustaka}

Studi pustaka dibutuhkan untuk membandingkan serta mengetahui penelitian sebelumnya yang berkaitan dengan pemodelan enterprise architecture, proses bisnis, infrastruktur, technology, dan TOGAF. Keselarasan visi dan misi dalam suatu organisasi sangat dibutuhkan model enterprise architecture untuk dijadikan acuan serta proses bisnis yang berjalan terintegrasi dengan baik.

\subsection{Model TOGAF}

Dalam membuat model TOGAF peneliti mengelompokan setiap elemen- elemen data ada proses business, data pendukung, applications yang dibangun digunakan untuk mensuport jalannya sistem, dan technology yang digunakan pada Universitas X Palembang. Data yang telah dikelompokan lalu dilakukan perhitungan menggunakan proses ststistik.

\subsection{Kesimpulan Analisis}

Kesimpulan yang didapat dari pemodelan architecture enterprise Universitas $\mathrm{X}$ yaitu proses bisnis yang dibuat harus terintegrasi dengan baik agar aplikasi yang ada bisa berjalan dengan baik, serta infrastructure yang ada mendukung semuanya. Serta hasil perhitungan yang didapat bias dijadikan ukuran architecture enterprise telah digunakan.

2.5 Dokumentasi, Pelaporan, dan Publikasi

Semua hasil penelitian pada Universitas x Palembang didokumentasikan dan melaporkan hasil penelitian kepada Universitas X Palembang serta mempublikasikan dalam bentuk jurnal yang terindex sinta 1-6.

\section{Hasil dan Analisis}

Universitas X Palembang memiliki bisnis utama dalam menyelenggarakan jasa pendidikan untuk masyarakat dengan menghasilkan lulusan siap kerja sehingga dapat memanfaatkan ilmunya secara langsung. Sistem informasi yang direncanakan adalah sistem informasi akademik yang berhubungan dengan organisasi pendidikan.Visi universitas yaitu menjadi Universitas terdepan dibidang Teknologi Informasi \& Komputer, Berwawasan Global dan Menjadi Pusat Unggulan dibidang Ilmu Pengetahuan, Teknologi dan Seni yang mendukung Pembangunan Nasional serta Berorientasi pada Kepentingan Masyarakat, Bangsa dan Negara. Misinya "Menjadi pusat layanan data dan informasi yang unggul dilingkungan". Dalam membangun dan mengembangkan system informasi guna membantu civitas bisnis untuk mencapai tujuan organisasi serta layanan yang berkualitas bagi stakeholder, system informasi harus selaras dengan arah strategi organisasi [12].
Model enterprise architecture pada sistem informasi akademik digunakan untuk mendukung proses bisnis yang berjalan serta terintegrasi dengan baik [13]. Peneliti membuat model enterprise architecture di Universitas mengacu pada empat proses TOGAF yaitu architecture business, architecture data, architecture application, dan architecture technology. Architecture Business adalah modeloperasional organisasi yang merealisasikan strategi bisnis organisasi [14]..Meliputi kebutuhan proses bisnis pada Universitas X yang mengacu pada visi dan misi dari Universitas $\mathrm{X}$ Palembang, guna mengetahui serta memahami aktifitas yang sedang berjalan untuk bisa terintegrasi dengan baik. Prinsip dari value chain yaitu bagaimana memetakan seluruh proses kerja atau aktivitas dalam institusi tersebut ke dalam dua bagian yaitu, aktivitas utama dan aktivitas pendukung [15]. Proses bisinis Universitas X Palembang bisa dilihat pada Tabel 1 .

Tabel 1. Proses Bisnis Eksisting dan Dukungan Sistem Informasi

\begin{tabular}{|c|c|c|c|}
\hline No & $\begin{array}{l}\text { ProsesB } \\
\text { usiness }\end{array}$ & SubProsesBisnis & $\begin{array}{l}\text { ValueCh } \\
\text { ain } \\
\text { Support }\end{array}$ \\
\hline A & PMB & & \\
\hline A. 1 & Informasi & $\begin{array}{l}\text { Informasi Tentang } \\
\text { Web Universitas X }\end{array}$ & PMB \\
\hline A. 2 & \multirow[t]{2}{*}{$\begin{array}{l}\text { Pembaya } \\
\text { ran ke } \\
\text { Bank }\end{array}$} & $\begin{array}{l}\text { Memasukkan Kode } \\
\text { Jalur dan Tanggal } \\
\text { Lahir. }\end{array}$ & PMB \\
\hline A. 3 & & $\begin{array}{l}\text { Mahasiswa } \\
\text { Mendapatkan } \\
\text { PMB dade } \\
\text { PMB. }\end{array}$ & PMB \\
\hline A. 4 & $\begin{array}{l}\text { Login } \\
\text { dan } \\
\text { Pendaftar } \\
\text { an }\end{array}$ & $\begin{array}{l}\text { Print Kartu Bukti } \\
\text { Pendaftaran dan } \\
\text { Print Kartu Ujian. }\end{array}$ & PMB \\
\hline A. 5 & Tes & $\begin{array}{l}\text { Tes tertulis untuk } \\
\text { disajikan ke dewan } \\
\text { yudisium. }\end{array}$ & PMB \\
\hline A. 6 & $\begin{array}{l}\text { Pengumu } \\
\text { man } \\
\text { Ujian }\end{array}$ & $\begin{array}{l}\text { Pengumuman } \\
\text { Yudisium PMB. }\end{array}$ & PMB \\
\hline A. 7 & $\begin{array}{l}\text { Mengisi } \\
\text { Data } \\
\text { Profil } \\
\text { Mahasis } \\
\text { wa }\end{array}$ & $\begin{array}{ll}\text { Mengisi } & \text { Profil } \\
\text { Mahasiswa. } & \end{array}$ & PMB \\
\hline A. 8 & $\begin{array}{l}\text { Rekap } \\
\text { Mahasis } \\
\text { wa Baru }\end{array}$ & $\begin{array}{l}\text { Merekap Data } \\
\text { Pendaftar } \\
\text { Mahasiswa Baru. }\end{array}$ & PMB \\
\hline B & $\begin{array}{l}\text { Registra } \\
\text { si }\end{array}$ & & \\
\hline B. 1 & $\begin{array}{l}\text { Pembaya } \\
\text { ran } \\
\text { Semester } \\
-1\end{array}$ & $\begin{array}{ll}\text { Pembayaran } & \text { Biaya } \\
\text { Pendidikan } & \\
\text { Mahasiswa } & \text { Baru } \\
\text { sem 1. } & \\
& \end{array}$ & $\begin{array}{l}\text { Registras } \\
\text { i }\end{array}$ \\
\hline
\end{tabular}




\begin{tabular}{|c|c|c|c|}
\hline B. 2 & $\begin{array}{l}\text { Registras } \\
\text { i } \\
\text { Mahasis } \\
\text { wa Baru }\end{array}$ & $\begin{array}{l}\text { Login, Isi Form, } \\
\text { Sistem Mengkopi } \\
\text { ke Data Mahasiswa. }\end{array}$ & $\begin{array}{l}\text { Registras } \\
\text { i }\end{array}$ \\
\hline B. 3 & $\begin{array}{l}\text { Cetak } \\
\text { Kartu } \\
\text { Tanda } \\
\text { Mahasis } \\
\text { wa } \\
\text { (KTM) }\end{array}$ & Cetak KTM. & $\begin{array}{l}\text { Registras } \\
\text { i }\end{array}$ \\
\hline B.4 & \multirow[t]{2}{*}{$\begin{array}{l}\text { Manajem } \\
\text { en Akun }\end{array}$} & $\begin{array}{l}\text { Autentifikasi Akun } \\
\text { univ x }\end{array}$ & TIPD \\
\hline B.5 & & Pengelolaan Akun. & TIPD \\
\hline B.6 & & $\begin{array}{l}\text { Perubahan } \\
\text { Password }\end{array}$ & TIPD \\
\hline B.7 & $\begin{array}{l}\text { Manajem } \\
\text { en } \\
\text { keuangan }\end{array}$ & $\begin{array}{l}\text { Manajemen } \\
\text { Keuangan univ x }\end{array}$ & \\
\hline $\mathrm{C}$ & KRS & & \\
\hline C. 1 & $\begin{array}{l}\text { Entri } \\
\text { Data } \\
\text { Kurikulu } \\
\text { m }\end{array}$ & $\begin{array}{l}\text { Memasukkan } \\
\text { Kurikulum yang } \\
\text { Berlaku. }\end{array}$ & $\begin{array}{l}\text { Pra } \\
\text { Perkuliah } \\
\text { an }\end{array}$ \\
\hline C. 2 & $\begin{array}{l}\text { Entri } \\
\text { Penjadwa } \\
\text { lan }\end{array}$ & $\begin{array}{l}\text { Memasukkan } \\
\text { Jadwal. }\end{array}$ & $\begin{array}{l}\text { Pra } \\
\text { Perkuliah } \\
\text { an }\end{array}$ \\
\hline C. 3 & $\begin{array}{l}\text { Konsulta } \\
\text { si dengan } \\
\text { DPA }\end{array}$ & $\begin{array}{lr}\text { Konsultasi } & \text { dengan } \\
\text { DPA } & \text { (Dosen } \\
\text { Penasehat } & \\
\text { Akademik) } & \text { Mata } \\
\text { Kuliah } & \text { yang } \\
\text { Diambil } & \\
\text { Mahasiswa. } & \\
\end{array}$ & KRS \\
\hline C. 4 & $\begin{array}{l}\text { KRS } \\
\text { Semester } \\
1\end{array}$ & $\begin{array}{l}\text { Peng KRS-an } \\
\text { semester } 1 .\end{array}$ & KRS \\
\hline C. 5 & \multirow[t]{3}{*}{$\begin{array}{l}\text { Pengisian } \\
\text { KRS } \\
\text { Mahasis } \\
\text { wa Lama }\end{array}$} & $\begin{array}{lr}\text { Update Data } & \text { Profil } \\
\text { dan Pengisian Mata } \\
\text { Kuliah r yang } \\
\text { Diambil. }\end{array}$ & KRS \\
\hline C.6 & & Approved DPA. & KRS \\
\hline C.7 & & Cetak KRS. & KRS \\
\hline $\mathrm{D}$ & $\begin{array}{l}\text { Perkulia } \\
\text { han }\end{array}$ & & \\
\hline D.1 & $\begin{array}{l}\text { Informasi } \\
\text { Akademi } \\
\text { k }\end{array}$ & $\begin{array}{l}\text { Informasi Tentang } \\
\text { Akademik. }\end{array}$ & $\begin{array}{l}\text { Perkuliah } \\
\text { an }\end{array}$ \\
\hline D. 2 & \multirow[t]{2}{*}{$\begin{array}{l}\text { Perkuliah } \\
\text { an }\end{array}$} & Proses Perkuliahan. & $\begin{array}{l}\text { Perkuliah } \\
\text { an }\end{array}$ \\
\hline D. 3 & & Kuliah Praktk. & $\begin{array}{l}\text { Perkuliah } \\
\text { an }\end{array}$ \\
\hline $\mathbf{E}$ & $\begin{array}{l}\text { Presensi } \\
\text { Online }\end{array}$ & $\begin{array}{l}\text { Pengelolaan } \\
\text { Ruangan Kelas.dan } \\
\text { daftar hadir }\end{array}$ & Persensi \\
\hline $\mathbf{F}$ & \multirow{2}{*}{$\begin{array}{l}\text { Materi } \\
\text { media } \\
\text { perkulia } \\
\text { han }\end{array}$} & $\begin{array}{l}\text { Managemen Journal } \\
\text { dengan Open Jurnal } \\
\text { Sistem (OJS). }\end{array}$ & PPM \\
\hline F.1 & & $\begin{array}{l}\text { Kuis Perkuliahan } \\
\text { dengan E-Quiz. }\end{array}$ & $\begin{array}{l}\text { Perkuliah } \\
\text { an }\end{array}$ \\
\hline
\end{tabular}

\begin{tabular}{|c|c|c|c|}
\hline F.2 & & $\begin{array}{l}\text { Download Materi } \\
\text { (E-Materi). }\end{array}$ & $\begin{array}{l}\text { Perkuliah } \\
\text { an }\end{array}$ \\
\hline F.3 & & $\begin{array}{l}\text { Pembelajaran E- } \\
\text { Learning. }\end{array}$ & $\begin{array}{l}\text { Perkuliah } \\
\text { an }\end{array}$ \\
\hline $\mathbf{G}$ & $\begin{array}{l}\text { Pratiku } \\
\text { m }\end{array}$ & $\begin{array}{l}\text { Praktek di ruang } \\
\text { pratikum }\end{array}$ & $\begin{array}{l}\text { Perkuliah } \\
\text { an }\end{array}$ \\
\hline $\mathbf{H}$ & UTS & & \\
\hline H.1 & $\begin{array}{l}\text { Pengurus } \\
\text { an Syarat }\end{array}$ & $\begin{array}{l}\text { Pengecekan Syarat- } \\
\text { Syarat Ujian }\end{array}$ & $\begin{array}{l}\text { Perkuliah } \\
\text { an }\end{array}$ \\
\hline Н.2 & $\begin{array}{l}\text { Ujian. } \\
\text { Ujian } \\
\text { Tengah } \\
\text { Semester } \\
\text { (UTS) }\end{array}$ & $\begin{array}{l}\text { Persiapan } \\
\text { Pelaksanaan Ujian. } \\
\text { Pelaksaaan Ujian. } \\
\text { Penilaian Ujian. }\end{array}$ & UTS \\
\hline I & UAS & & \\
\hline I.1 & $\begin{array}{l}\text { Pengurus } \\
\text { an Syarat } \\
\text { Ujian. }\end{array}$ & $\begin{array}{l}\text { Pengecekan Syarat- } \\
\text { Syarat Ujian }\end{array}$ & $\begin{array}{l}\text { Perkuliah } \\
\text { an }\end{array}$ \\
\hline I. 2 & $\begin{array}{l}\text { Ujian } \\
\text { Akhir } \\
\text { Semester } \\
\text { (UAS) }\end{array}$ & $\begin{array}{l}\text { Persiapan } \\
\text { pelaksanaan ujian. } \\
\text { Pelaksaaan ujian. } \\
\text { Penilaian ujian. }\end{array}$ & UAS \\
\hline $\mathrm{J}$ & KHS & & \\
\hline J.1 & $\begin{array}{l}\text { Nilai } \\
\text { setiap } \\
\text { matkul }\end{array}$ & $\begin{array}{l}\text { Lihat Kartu Hasil } \\
\text { belajar selama } 1 \\
\text { semester }\end{array}$ & KHS \\
\hline K & $\begin{array}{l}\text { Tugas } \\
\text { Akhir } \\
\text { Pendadar } \\
\text { an }\end{array}$ & & \\
\hline K.1 & $\begin{array}{l}\text { Berkas } \\
\text { Pendadar } \\
\text { an }\end{array}$ & $\begin{array}{l}\text { Ujian Pendadaran } \\
\text { Sidang Penilaian } \\
\text { pendadaran. }\end{array}$ & $\begin{array}{l}\text { Tugas } \\
\text { Akhir }\end{array}$ \\
\hline $\mathbf{L}$ & $\begin{array}{l}\text { Bimbing } \\
\text { an TA }\end{array}$ & $\begin{array}{l}\text { Jadwal bimbingan } \\
\text { Tugas Akhir }\end{array}$ & $\begin{array}{l}\text { Tugas } \\
\text { Akhir }\end{array}$ \\
\hline M & $\begin{array}{l}\text { Yudisiu } \\
\text { m }\end{array}$ & & \\
\hline M.1 & $\begin{array}{l}\text { Yudisium } \\
\text { Online }\end{array}$ & $\begin{array}{l}\text { Pendaftaran } \\
\text { Yudisium. }\end{array}$ & Yudisium \\
\hline $\mathrm{N}$ & Wisuda & & \\
\hline N.1 & Wisuda & Pendaftaran & Wisuda \\
\hline N.2 & Wisuda & Alumni & Wisuda \\
\hline N.3 & $\begin{array}{l}\text { Alumni } \\
\text { dan } \\
\text { Tracer } \\
\text { Study } \\
\text { Kartu } \\
\text { alumni }\end{array}$ & $\begin{array}{l}\text { Legalisir dan cetak } \\
\text { kartu Alumni }\end{array}$ & \\
\hline $\mathbf{O}$ & $\begin{array}{l}\text { Aplikasi } \\
\text { Orang } \\
\text { tua }\end{array}$ & Data mahasiswa & KHS \\
\hline O.1 & $\begin{array}{l}\text { Data } \\
\text { Online }\end{array}$ & $\begin{array}{l}\text { Presensi } \\
\text { mahasiswa, nilai } \\
\text { mahasiswa }\end{array}$ & Presensi \\
\hline
\end{tabular}

Architecture data digunakan untuk melihat data yang terkait dengan aktifitas yang berjalan pada Universitas X Palembang agar data yang berjalan secara bersamaan 
tidak terjadi duplikat data serta bisa terintegrasi dengan baik. Data yang terkait dengan proses bisnis Universitas $\mathrm{X}$ Palembang dapat dilihat pada Tabel 2.

Tabel 2. Proses bisnis dan Data Universitas X

\begin{tabular}{|c|c|c|}
\hline No & $\begin{array}{l}\text { Proses } \\
\text { Bisnis }\end{array}$ & Data \\
\hline 1 & PMB & $\begin{array}{l}\text { Informasi, pembayaran, kode } \\
\text { dan pin, ujian, pengumuman, isi } \\
\text { data profil, rekap mahasiswa } \\
\text { baru. }\end{array}$ \\
\hline 2 & $\begin{array}{l}\text { Pemba } \\
\text { yaran }\end{array}$ & $\begin{array}{l}\text { Pembayaran sem } 1 \text {, dapat user } \\
\text { dan password, reservasi. }\end{array}$ \\
\hline 3 & $\begin{array}{l}\text { Registr } \\
\text { asi }\end{array}$ & $\begin{array}{l}\text { Login, Registrasi data, cetak } \\
\text { Kartu Tanda Mahasiswa. }\end{array}$ \\
\hline 4 & $\begin{array}{l}\text { Pra } \\
\text { Perkuli } \\
\text { ahan }\end{array}$ & $\begin{array}{l}\text { Kuliah umum,pertemuan orang } \\
\text { tua, pengenalan kampus. }\end{array}$ \\
\hline 5 & KRS & $\begin{array}{l}\text { Mata kuliah, jadwal kuliah, } \\
\text { beban SKS, cetak KRS. }\end{array}$ \\
\hline 6 & Dosen & $\begin{array}{l}\text { Dosen akademik, jadwal ngajar, } \\
\text { pengampu mata kuliah, } \\
\text { penelitian, jabatan, evaluasi } \\
\text { kinerja dosen. }\end{array}$ \\
\hline 7 & $\begin{array}{l}\text { Perkuli } \\
\text { ahan }\end{array}$ & $\begin{array}{l}\text { Proses perkuliahan, kuliah } \\
\text { praktek, jurnal, download } \\
\text { materi, pelaksanaan pelatihan. }\end{array}$ \\
\hline 8 & $\begin{array}{l}\text { Presens } \\
\text { i } \\
\text { Online }\end{array}$ & $\begin{array}{l}\text { Absen yang dilakukan secara } \\
\text { ontime dan real time } \\
\text { menggunakan kartu dan sidik } \\
\text { jari. }\end{array}$ \\
\hline 9 & $\begin{array}{l}\text { Presens } \\
\text { i } \\
\text { manual }\end{array}$ & $\begin{array}{l}\text { Absen manual yang } \\
\text { menggunakan tanda tangan. }\end{array}$ \\
\hline 10 & Materi & $\begin{array}{l}\text { Materi perkuliahan, kuis, } \\
\text { latihan. }\end{array}$ \\
\hline 11 & $\begin{array}{l}\text { Pratiku } \\
\mathrm{m}\end{array}$ & Praktek khusus \\
\hline 12 & UTS & $\begin{array}{l}\text { at ujian, pelaksanaan ujian } \\
\text { ah semester, penilaian ujian. }\end{array}$ \\
\hline 13 & UAS & $\begin{array}{l}\text { Syarat ujian, pelaksanaan akhir } \\
\text { semsester, penilaian ujian }\end{array}$ \\
\hline 14 & KHS & $\begin{array}{l}\text { Kartu hasil belajar selama } 1 \\
\text { semsester }\end{array}$ \\
\hline 15 & $\mathrm{KKN}$ & $\begin{array}{l}\text { Pendaftaran kuliah kerja nyata, } \\
\text { pembekalan kuliah kerja nyata, }\end{array}$ \\
\hline 16 & TBQ & $\begin{array}{l}\text { Pendaftaran baca tulis al-quran, } \\
\text { tes BTQ }\end{array}$ \\
\hline 17 & $\begin{array}{l}\text { Elearni } \\
\text { ng }\end{array}$ & $\begin{array}{l}\text { Elearning pengganti kuliah } \\
\text { secara online. }\end{array}$ \\
\hline 18 & $\begin{array}{l}\text { SIMPU } \\
\text { S }\end{array}$ & $\begin{array}{l}\text { Pendaftaran data, pinjam buku, } \\
\text { pengambalian } \\
\text { perpustakaan. }\end{array}$ \\
\hline 19 & $\begin{array}{l}\text { Evaluas } \\
\text { i }\end{array}$ & $\begin{array}{l}\text { Indek kinerja dosen, audit mutu } \\
\text { internal, penilaian dosen, } \\
\text { pengisian kuisioner efektifitas } \\
\text { pembelajaran. }\end{array}$ \\
\hline 20 & Wifi & Autentifikasi akun, pengelolaan \\
\hline
\end{tabular}

\begin{tabular}{|c|c|c|}
\hline 21 & $\begin{array}{l}\text { Tugas } \\
\text { Akhir }\end{array}$ & $\begin{array}{l}\text { akun, perubahaan password. } \\
\text { Berkas ujian, ujian pendadaran, } \\
\text { siding nilai pendadaran. }\end{array}$ \\
\hline 22 & $\begin{array}{l}\text { Bimbin } \\
\text { gan TA }\end{array}$ & $\begin{array}{l}\text { Bimbingan tugas akhir secara } \\
\text { online dengan dosen. }\end{array}$ \\
\hline 23 & $\begin{array}{l}\text { Yudisiu } \\
\mathrm{m}\end{array}$ & $\begin{array}{l}\text { Pendaftaran yudisium, } \\
\text { pelaksanaan yudisium. }\end{array}$ \\
\hline 24 & Wisuda & $\begin{array}{l}\text { Pendaftaran wisuda, alumni, } \\
\text { legalisir ijazah. }\end{array}$ \\
\hline 25 & Alumni & $\begin{array}{l}\text { Terdaftar sebagai alumni, cetak } \\
\text { kartu alumni }\end{array}$ \\
\hline 26 & $\begin{array}{l}\text { Aplikas } \\
\text { i Orang } \\
\text { Tua }\end{array}$ & $\begin{array}{l}\text { Forum khusus orang tua } \\
\text { memantau kehadiran dan nilai } \\
\text { anak di perkuliahan. }\end{array}$ \\
\hline
\end{tabular}

Architecture application yang ada pada Universitas $\mathrm{X}$ Palembang harus terintegrasi dengan data sistem informasi akademik, sehingga aplikasi dan data dapat berjalan bersamaan secara online. Adapun kebutuhan aplikasi yang digunakan pada Universitas X Palembang terdapat pada Tabel 3.

Tabel 3. Kebutuhan Aplikasi pada Universitas X

\begin{tabular}{|c|c|}
\hline STRATEGI & POTENSI UTAMA \\
\hline $\begin{array}{l}\text {-Sistem Analisis } \\
\text { PMB } \\
\text {-Sistem Analisis dan } \\
\text { Riset Pemasaran } \\
\text {-Sistem Manajemen } \\
\text { Kurikulum } \\
\text {-Sistem Relasi Data } \\
\text { Alumni Analisis } \\
\text {-Sistem Kemajuan Studi } \\
\text {-Sistem Nilai } \\
\text {-Sistem Anggaran } \\
\text {-Sistem Pelaporan } \\
\text { Akademik Pad }\end{array}$ & $\begin{array}{l}\text {-Sistem Informasi Akademik } \\
\text { Berbasis WEB } \\
\text {-Sistem Pendaftaran On-line } \\
\text {-Sistem Informasi Nilai On-line } \\
\text {-Sistem Layanan Relasi Alumni } \\
\text { On-line } \\
\text {-Sistem Informasi Akademik } \\
\text {-Sistem Informasi Akademik } \\
\text { Berbasis Layanan WAP } \\
\text {-Sistem Profile Lembaga } \\
\text { berbasis Multimedia } \\
\text {-Sistem Layanan orang tua }\end{array}$ \\
\hline $\begin{array}{c}\text { KUNCI } \\
\text { OPERASIONAL }\end{array}$ & PENDUKUNG \\
\hline
\end{tabular}

Architecture technology merupakan konfigurasi infrastruktur yang dibutuhkan untuk menjalankan aplikasi-aplikasi pada arsitrktur system informasi [14]. tahap mendefinisikan teknologi yang digunakan pada Universitas X Palembang untuk mendukung jalannya aplikasi dan data yang terkait. 
Bisa dilihat pada Tabel 4.

Tabel 4. Technology pendukung

\begin{tabular}{|l|l|c|}
\hline NO & NAMA BARANG & JUMLAH \\
\hline 1 & Personal Komputer (PC) & 850 \\
2 & Laptop & 10 \\
3 & Printer & 70 \\
4 & Server & 25 \\
\hline
\end{tabular}

\section{Kesimpulan}

Kesimpulan yang dapat ditarik dari penelitian yaitu perancangan arsitekture enterprise di sistem akademik, arsitektur data dan teknologi yang didapat dalam penelitian ini yang saling terintergrasi dan terhubung. Strategi model bisnis yang dibuat harus dapat memiliki ruang lingkup yang lengkap dan stabil untuk waktu yang panjang. Pengembangan model enterprise architecture dapat dikembangkan sesuai dengan strategi organisasi yang dimiliki, dengan acuan enterprise architecture. Architecture yang dirancang akan menentukan sistem informasi akademik dimasa yang akan datang. Penelitian ini terdapat beberapa hal yang bisa dikembangkan untuk penelitian selanjutnya, yaitu menganalisis dampak arsitektur aplikasi konseptual dengan aplikasi yang sudah ada di terapkan enterprise architecture, sebisa mungkin diusahakan mempertahankan sebagian besar aplikasi yang ada. Hal ini berhubungan dengan estimasi biaya dan usaha, semakin banyak aplikasi yang ada dipertahankan semakin sedikit biaya dan usaha yang dilakukan.

\section{Ucapan terima kasih}

Penulis mengucapkan terima kasih sebesar-besarnya kepada Kementrian Riset dan Teknologi / Badan Riset dan Inovasi Nasional (BRIN) yang telah memberikan dana hibah. Universitas Teknokrat serta LPPM yang telah banyak membantu penulis dan memberikan wadah kepada penulis dalam melaksanakan penelitian.

\section{Daftar Pustaka}

[1] A. Alwadain, E. Fielt, A. Korthaus, and M. Rosemann, "NU SC," DATAK, 2015, doi: 10.1016/j.datak.2015.09.004.

[2] G. W. Sasmito, "PEMANFAATAN MODEL ENTERPRISE ARCHITECTURE PADA EACADEMIC POLITEKNIK HARAPAN BERSAMA,” vol. 2, no. 2, pp. 119-123, 2017.

[3] R. T. Subagio, "Pemodelan Arsitektur Enterprise STMIK CIC Cirebon Menggunakan Enterprise Architecture Planning ( EAP )," vol. 1, no. 2, pp. 113-122, 2011.

[4] I. L. Sardi and K. Surendro, "Rekomendasi Perancangan Arsitektur Enterprise Pascamerger ( Studi kasus: Universitas Telkom )," vol. 1, no.
February, pp. 61-76, 2016, doi: 10.21108/indojc. 2016 .

[5] R. Setiawan et al., "PERANCANGAN ARSITEKTUR ENTERPRISE”, volume.12, no.1, pp.1-8, 2015.

[6] M. Rovers, "Copyright protected. Use is for Single Users only via a VHP Approved License. For information and printed versions please see www.vanharen.net," Van Haren Publ. Zaltbommel, pp. 11-148, 2017.

[7] M. K. Teknologi, "Jurnal iptek," volume 22, no.1, pp. 13-20, 2018.

[8] C. L. B. Azevedo et al., "Modeling resources and capabilities in enterprise architecture: A wellfounded ontology-based proposal for ArchiMate," Inf. Syst., pp. 1-28, 2015, doi: 10.1016/j.is.2015.04.008.

[9] R. T. Dirgahayu, H. Prihantoro, M. T. Informatika, F. T. Industri, and U. I. Indonesia, "Vol . 10 No . 1 Agustus 2017 ISSN : 1979-8415 POTRET PEMANFAATAN ARCHITECTURE ENTERPRISE Vol . 10 No . 1 Agustus 2017 ISSN : 1979-8415," vol. 10, no. 1, pp. 57-65, 2017.

[10] F. Thaib, A. R. Emanuel, P. Studi, T. Informatika, U. A. Yogyakarta, and J. Tengah, "Perancangan Enterprise Architecture UNIPAS Morotai Menggunakan TOGAF ADM Enterprise Architecture Design of UNIPAS Morotai Using TOGAF ADM," vol. 9, no. 1, pp. 1-8, 2020.

[11] T. Adm, "PERANCANGAN ENTERPRISE ARCHITECTURE TEKNOLOGI INFORMASI ADAPTIF DENGAN FRAMEWORK TOGAF PADA," vol. 05, no. 01, pp. 19-33, 2020.

[12] Y. T. Wiranti, R. Eliviani, V. Daningrum, and L. H. Atrinawati, "Pemodelan Arsitektur Enterprise Menggunakan Metode Togaf Pada Sekolah Tinggi Ilmu Ekonomi Madani Balikpapan,” pp. 15-26, 2019.

[13] A. Mubarok and D. S. Tjahjadi, "PEMODELAN ARSITEKTUR ENTERPRISE SISTEM INFORMASI CUSTOMER RELATIONSHIP MANAGEMENT MENGGUNAKAN," vol. 11, no. 28, pp. 231-240, 2019.

[14] I. S. Workshop, "IT Planning," technical workshop, pusilkom UI, 2008.

[15] L. Nur, A. Amalia, N. Ambarsari, F. R. Industri, and U. Telkom, "JURNAL TUGAS AKHIR UNIVERSITAS TELKOM ANALISIS DAN PERANCANGAN ENTERPRISE ARCHITECTURE SISTEM MANAJEMEN PENILAIAN PERFORMA BERBASIS SMART CITY," vol. 6, no. 2, pp. 7721-7733, 2019.

[16] Lathifah, Suaidah, "PENERAPAN ENTERPRISE ARCHITECTURE DALAM PENERIMAAN MAHASISWA BARU MENGGUNAKAN TOGAF PADA UNIVERSITAS X PALEMBANG," ISSN : 2407-4322, vol. 7, no. 3, 2020. 
First Author, Second Author, and Third Author (9 pt, italics) 